\title{
Effect of sex on nadir hematocrit and rates of acute kidney injury in coronary artery bypass
}

Alexander A. Brescia, MD, ${ }^{a}$ Xiaoting Wu, PhD, ${ }^{a}$ Gaetano Paone, MD, MHSA, ${ }^{\mathrm{b}}$ Michael Heung, MD, MS, ${ }^{\mathrm{a}}$ Theron A. Paugh, CCP, ${ }^{a}$ Kenneth G. Shann, CCP, ${ }^{c}$ David C. Fitzgerald, MPH, CCP, LP, ${ }^{d}$

Timothy A. Dickinson, MS, CCP, ${ }^{\mathrm{e}}$ David Sturmer, CCP, ${ }^{\mathrm{a}}$ Jeffrey Chores, CCP, ${ }^{\mathrm{f}}$ Andrew L. Pruitt, MD, ${ }^{\mathrm{g}}$ Haley Allgeyer, ${ }^{a}$ Sim Uppal, ${ }^{\mathrm{a}}$ Min Zhang, PhD, ${ }^{\mathrm{a}}$ Himanshu J. Patel, MD, ${ }^{\mathrm{a}}$ Richard L. Prager, MD, ${ }^{\mathrm{a}, \mathrm{h}}$ and Donald S. Likosky, $\mathrm{PhD},{ }^{\mathrm{a}, \mathrm{h}}$ on behalf of the PERForm Registry and the Michigan Society of Thoracic and Cardiovascular Surgeons Quality Collaborative

\section{ABSTRACT}

Objective: Findings from a large multicenter experience showed that sex influenced the relationship between low nadir hematocrit and increased risk of acute kidney injury after cardiac surgery. We explored whether sex-related differences persisted among patients undergoing isolated coronary artery bypass grafting.

Methods: We undertook a prospective, observational study of 17,363 patients without dialysis (13,137 male: $75.7 \%$; 4226 female: $24.3 \%$ ) undergoing isolated coronary artery bypass grafting between 2011 and 2016 across 41 institutions in the Perfusion Measures and Outcomes registry. Odds ratios between nadir hematocrit and stage 2 or 3 acute kidney injury were calculated, and the interaction of sex with nadir hematocrit was tested. The multivariable, generalized, linear mixed-effect model adjusted for preoperative and intraoperative factors and institution.

Results: Median nadir hematocrit was $22 \%$ among women and $27 \%$ among men $(P<.001)$. Women were administered a greater median net prime volume indexed to body surface area ( 407 vs $363 \mathrm{~mL} / \mathrm{m}^{2}$ ) and more red blood cell transfusions (55.5\% vs $24.3 \%$; both $P<.001)$. Acute kidney injury was higher among women $(6.0 \%$ vs $4.3 \%, P<.001)$. There was no effect of sex on the relationship between nadir hematocrit and acute kidney injury $(P=.67)$. Low nadir hematocrit was inversely associated with acute kidney injury (adjusted odds ratios per 1-unit increase in nadir hematocrit $0.96 ; 95 \%$ confidence interval, $0.93-0.98$ ); this effect was similar across sexes and independent of red blood cell transfusions.

Conclusions: We found no sex-related differences in the effect of nadir hematocrit on acute kidney injury after isolated coronary artery bypass grafting. However, the strong inverse relationship between anemia and acute kidney injury across sexes suggests the importance of reducing exposure to low nadir hematocrit. (J Thorac Cardiovasc Surg 2019;158:1073-80)

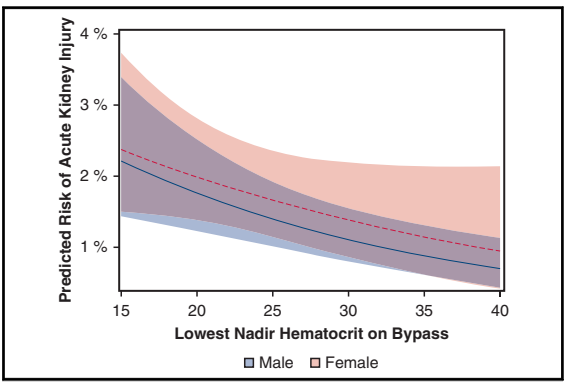

Relationship between nadir Hct during bypass and risk of stage 2 or $3 \mathrm{AKI}$.

\section{Central Message}

Unlike in prior studies, we found no interaction by sex in the relationship between low nadir Hct and AKI. Given its impact on AKI, anemia during isolated CABG should be avoided.

\section{Perspective}

Although sex does not modify the relationship between nadir Hct and AKI in an isolated CABG population, nadir Hct continues to confer an increased risk of AKI. These findings persisted after adjusting for baseline risk and $\mathrm{RBC}$ transfusions and reinforce the importance of reducing exposure to low nadir Hct on CPB.

See Commentary on page 1081.

\footnotetext{
From the ${ }^{a}$ University of Michigan, Ann Arbor, Mich; 'Division of Cardiac Surgery, Henry Ford Hospital, Detroit, Mich; ' Massachusetts General Hospital, Boston, Mass; ${ }^{\mathrm{d}}$ Medical University of South Carolina, Charleston, SC; ${ }^{\mathrm{e}}$ Mayo Clinic, Ro-

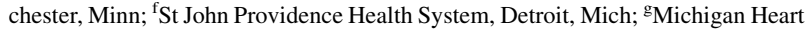
and Vascular Institute, St Joseph Mercy Hospital, Ann Arbor, Mich; and ${ }^{\mathrm{h}}$ PERForm Registry and The Michigan Society of Thoracic and Cardiovascular Surgeons Quality Collaborative, Ann Arbor, Mich.

A.A.B. is supported by the National Research Service Award postdoctoral fellowship (No. 5T32HL076123). D.S.L. is supported in part by the Agency for Healthcare Research and Quality under Grants R01HS026003 and R01HS022535. The opinions expressed in this document are those of the authors and do not reflect the official position of the Agency for Healthcare Research and Quality or the US Department of Health and Human Services. Support for the Michigan Society of Thoracic and Cardiovascular Surgeons Quality Collaborative is provided by the
}

Blue Cross and Blue Shield of Michigan (BCBSM) and Blue Care Network as part of the BCBSM Value Partnerships program. Although the BCBSM and Michigan Society of Thoracic and Cardiovascular Surgeons Quality Collaborative work collaboratively, the opinions, beliefs, and viewpoints expressed by the authors do not necessarily reflect the opinions, beliefs, and viewpoints of BCBSM or any of its employees.

Received for publication Nov 28, 2018; revisions received March 2, 2019; accepted for publication March 9, 2019; available ahead of print April 30, 2019.

Address for reprints: Donald S. Likosky, PhD, Section of Health Services Research and Quality, Department of Cardiac Surgery, University of Michigan Medica School, Ann Arbor, MI 48109 (E-mail: likosky@med.umich.edu) 0022-5223/\$36.00

Copyright (c) 2019 by The American Association for Thoracic Surgery https://doi.org/10.1016/j.jtcvs.2019.03.042 


$\begin{array}{ll}\text { Abbreviations and Acronyms } \\ \text { AKI } & =\text { acute kidney injury } \\ \text { BSA } & =\text { body surface area } \\ \text { CABG } & =\text { coronary artery bypass grafting } \\ \text { CI } & =\text { confidence interval } \\ \text { CPB } & =\text { cardiopulmonary bypass } \\ \text { Hct } & =\text { hematocrit } \\ \text { HR } & =\text { hazard ratio }\end{array}$

MSTCVS-QC $=$ Michigan Society of Thoracic and Cardiovascular Surgeons Quality Collaborative
$\mathrm{OR} \quad=$ odds ratio
PERForm $=$ Perfusion Measures and Outcomes RBC $=$ red blood cell

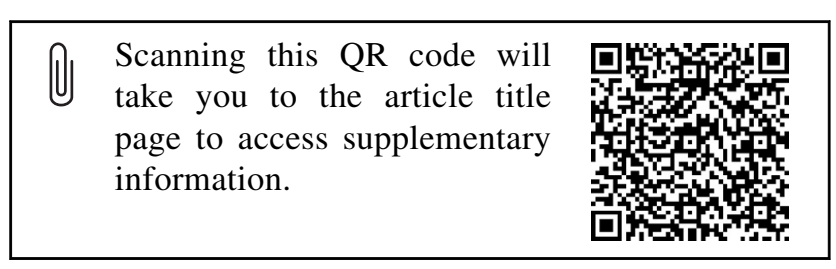

Patients undergoing isolated coronary artery bypass grafting (CABG) surgery are at risk for many morbid events, including acute kidney injury (AKI). Prior reports suggest that a spectrum of AKI develops in approximately $30 \%$ of patients, with $0.4 \%$ to $2 \%$ of patients requiring postoperative renal replacement therapy. ${ }^{1-4}$ Emerging literature has documented the risk of further sequelae due to even small increases in creatinine (stage $1 \mathrm{AKI}$ ), including an increased risk of mortality (hazard ratio [HR], 1.56; 95\% confidence interval [CI], 1.14-2.12), readmission (HR, 1.31; CI, 1.10-1.57) and an approximately 3 -fold increased risk of developing end-stage renal disease (HR, 2.92; CI, 1.87-4.55). ${ }^{5,6}$

Prior studies have documented an inverse relationship between a patient's intraoperative exposure to low nadir hematocrit (Hct) during cardiopulmonary bypass (CPB) and risk of AKI. Although women may be uniquely susceptible to AKI given their increased risk of lower nadir Hct secondary to hemodilution, prior reports have shown conflicting results. $^{7-9}$ These reports have included a heterogeneous population of cardiac procedures and likely cannot be generalizable to isolated CABG procedures. Thus, efforts aimed at reducing a patient's risk of AKI after isolated $\mathrm{CABG}$ requires further investigation into a potential interaction between sex and intraoperative anemia.

In the present analysis, we identified whether sex modifies the relationship between intraoperative anemia and AKI in the setting of isolated CABG (Figure E1). To do so, we conducted an observational study of nondialysis-dependent patients undergoing isolated CABG across 41 hospitals participating in a multiinstitutional quality improvement database.

\section{PATIENTS AND METHODS}

This study was approved by the Institutional Review Board of the University of Michigan Health System (HUM00117260, notice of determination of "Not Regulated").

\section{Patient Population}

The Perfusion Measures and Outcomes (PERForm) registry is organizationally structured within the Michigan Society of Thoracic and Cardiovascular Surgeons Quality Collaborative (MSTCVS-QC). The MSTCVS-QC began in 2001 as a cardiac surgeon-led quality collaborative embedded in the MSTCVS, and in 2005, it became partially funded by the Blue Cross/ Blue Shield of Michigan insurance company. The collaborative meets quarterly to review various processes and outcomes, and to facilitate and evaluate quality improvement studies.

All programs in the MSTCVS-QC use The Society of Thoracic Surgeons data collection forms and submit data on a quarterly basis to the MSTCVS-QC data warehouse. The PERForm registry is the official registry of the American Society of ExtraCorporeal Technology (http://www. amsect.org), and the American Society of ExtraCorporeal Technology in turn is the PERForm registry's official societal partner. The PERForm registry contains information related to the care and conduct of cardiovascular perfusion practices. A list of fields and definitions may be found at http:// www.performregistry.org. Each center's surgical record is merged with a perfusion record from the PERForm registry. ${ }^{10}$ Participating centers are routinely audited for data validity and accuracy as part of the MSTCVSQC audit system.

We included patients who underwent isolated $\mathrm{CABG}$ with use of $\mathrm{CPB}$ at any of the 41 centers participating in the PERForm registry between July 11, 2011, and September 30, 2016. We excluded patients undergoing dialysis preoperatively or $\mathrm{CPB}$ with circulatory arrest, and those with a ventricular assist device.

\section{Measures}

The primary outcome for this analysis was stage 2 or $3 \mathrm{AKI}$, using the Acute Kidney Injury Network creatinine criteria (defined as a 2-fold or greater increase in serum creatinine from baseline, creatinine increase to $\geq 4.0 \mathrm{mg} / \mathrm{dL}$ with an acute increase $>0.5 \mathrm{mg} / \mathrm{dL}$, or acute dialysis requirement). ${ }^{11}$ We report crude rates of transfusions, hospital operative mortality, reoperation for bleeding, prolonged ventilation time more than 24 hours, total intensive care unit stay more than 24 hours, need for ultrafiltration or dialysis, low cardiac output, new-onset atrial fibrillation, sepsis, postoperative length of stay, and 30-day readmission.

\section{Statistical Analysis}

Categoric variables were presented as percentages and continuous variables as mean (standard deviation) for univariate analyses. Chi-square and Fisher exact tests were used to test statistical significance for categoric variables, and Wilcoxon rank-sum tests were used for continuous variables.

Missing values of categoric variables with less than $1 \%$ missingness were imputed with their lowest risk values. Missing values of continuous variables were imputed to conditional median by sex. The number of missing observations for variables included in the final model and method of imputation are shown in Table E1. Variables were selected using a logistic regression model with the Least Absolute Shrinkage and Selection Operator penalized method. The final model included preoperative and intraoperative factors: surgical year, age, sex, body surface area (BSA), diabetes, peripheral vascular disease, chronic lung disease, preoperative Hct, 
TABLE 1. Preoperative patient characteristics

\begin{tabular}{|c|c|c|c|}
\hline Variable & Female & Male & $P$ value \\
\hline No. of procedures & 4226 & 13,137 & \\
\hline Age, median [IQR] y & $67[59-74]$ & 65 [58-72] & $<.001$ \\
\hline$<60$ & 25.5 & 30.2 & \\
\hline $60-69$ & 33.8 & 36.7 & \\
\hline $70+$ & 40.7 & 33.1 & \\
\hline
\end{tabular}

$\begin{array}{lrr}\text { BSA, } \mathrm{m}^{2} & & 0.7 \\ <1.60 & 10.6 & 6.1 \\ 1.60-1.79 & 27.1 & 24.1 \\ 1.80-1.99 & 33.3 & 69.2 \\ \geq 2.00 & 28.9 & \end{array}$

\section{Risk factors}

Diabetes mellitus, \% yes

Vascular disease, \% yes $\quad 16.8$

Moderate-severe COPD, \% yes

11.8

Last preoperative creatinine, $\mathrm{mg} / \mathrm{dL}$, median [IQR]

Hct, \%

$\begin{array}{ll}<33 & 20.6 \\ 33-36 & 30.3 \\ 37-40 & 31.9 \\ 41+ & 17.2\end{array}$

\section{Hypertension, \% yes}

EGFR $<30 \mathrm{~mL} / \mathrm{min} / 1.73 \mathrm{~m}^{2}, \%$ yes

EGFR, $\mathrm{mL} / \mathrm{min} / 1.73 \mathrm{~m}^{2}$

$$
\begin{aligned}
& \geq 90 \\
& 60-90 \\
& 30-60 \\
& 15-30 \\
& <15
\end{aligned}
$$

$\begin{array}{rr}20.6 & 8.1 \\ 30.3 & 14.2 \\ 31.9 & 28.1 \\ 17.2 & 49.6\end{array}$

\section{8}

3.1

26.5

42.4

28.0

2.9

0.2

$<.001$

0.7

\begin{tabular}{|c|c|c|c|}
\hline Last WBC count $\times 10^{9} / \mathrm{L}$, median $[\mathrm{IQR}]$ & 7.8 [6.3-9.5] & 7.5 [6.2-9.2] & $\begin{array}{l}<.001 \\
<.001 \\
\end{array}$ \\
\hline Current smoker within $30 \mathrm{~d}, \%$ & 22.6 & 22.7 & .949 \\
\hline \multicolumn{4}{|l|}{ Cardiac history } \\
\hline $\mathrm{CHF}, \%$ yes & 17.4 & 12.8 & $<.001$ \\
\hline Prior myocardial infarction, $\%$ & 54.4 & 53.2 & .15 \\
\hline Prior $\mathrm{CABG}, \%$ & 1.5 & 2.0 & .04 \\
\hline Prior cardiac surgery, $\%$ & 2.2 & 2.5 & .34 \\
\hline \multicolumn{4}{|l|}{ Cardiac anatomy and function } \\
\hline \multicolumn{4}{|l|}{ LVEF, \% } \\
\hline$<40$ & 12.9 & 15.7 & \\
\hline $40-49$ & 13.4 & 15.4 & \\
\hline $50-59$ & 32.3 & 34.7 & \\
\hline \multirow[t]{2}{*}{$60+$} & 41.4 & 34.1 & \\
\hline & & & $<.001$ \\
\hline Left main disease $\geq 50 \%$ stenosis, $\%$ yes & 34.5 & 33.9 & .44 \\
\hline $3+$ diseased vessels, $\%$ yes & 74.3 & 79.6 & $<.001$ \\
\hline \multicolumn{4}{|l|}{ Acuity } \\
\hline Elective & 34.9 & 41.3 & \\
\hline Urgent & 61.1 & 56.2 & \\
\hline Emergency/salvage & 3.9 & 2.5 & \\
\hline
\end{tabular}

6.1

24.1

69.2 
TABLE 1. Continued

\begin{tabular}{cccc}
\hline Variable & Female & Male & $\boldsymbol{P}$ value \\
\hline & & $<.001$ \\
STS mortality and morbidity risk score, median $\%[\mathrm{IQR}]$ & $14[10-21]$ & $10[7-16]$ & $<.001$ \\
\hline
\end{tabular}

$I Q R$, Interquartile range; $B S A$, body surface area; $C O P D$, chronic obstructive pulmonary disease; $H c t$, hematocrit; $E G F R$, estimated glomerular filtration rate; WBC, white blood cell; $C H F$, congestive heart failure; $C A B G$, coronary artery bypass grafting; $L V E F$, left ventricular ejection fraction; STS, Society of Thoracic Surgeons.

estimated glomerular filtration rate, white blood cell, hypertension, congestive heart failure, New York Heart Association classification, ejection fraction, acuity status, number of diseased vessels, perfusion time, crossclamp time, static volume indexed to BSA, preoperative or intraoperative intraaortic balloon pump, total volume of fluid in during operation, use of acute normovolemic hemodilution, total cardioplegia volume, lowest temperature during the operation, furosemide use, net prime volume indexed to BSA, and lowest Hct during the operation (and its interaction with sex). The final generalized linear mixed model used a logit link function and included centers as the random effect to account for the clustering of patients within each center.

Sensitivity analyses were performed by analyzing the effect of lowest Hct separately by strata of sex. The effect of nadir Hct on AKI is reported as the odds ratio (OR) per 1-unit increase in nadir Hct. The predicted probability of AKI, fixing the adjusted covariates at the median of the continuous variables or the mode values of the categoric variables (along with $95 \%$ CIs), was plotted separately for men and women. Sensitivity analyses were also performed to assess the effect of sex on the relationship between nadir Hct and AKI when stratified by red blood cell (RBC) transfusion status. All statistical calculations used R version 3.4.0 and SAS 9.4 (SAS Institute, Inc, Cary, NC). $P$ values of less than .05 (2-tailed) were considered statistically significant.

\section{RESULTS}

Between July 11, 2011, and September 30, 2016, 17,873 patients underwent isolated CABG at the 41 participating centers. After excluding patients presenting on dialysis $(n=443)$, using a ventricular assist device $(n=2)$, undergoing intraoperative circulatory arrest $(\mathrm{n}=8)$, undergoing another cardiac procedure $(\mathrm{n}=10)$, or with missing data for AKI staging $(\mathrm{n}=155)$, the final study population consisted of 17,363 patients (13,137 male and 4226 female).

Preoperative patient characteristics are listed in detail in Table 1. Women were slightly older and had higher rates of preoperative diabetes, vascular disease, hypertension, and congestive heart failure than men. Additionally, women had lower baseline Hct and estimated glomerular filtration rate, but higher procedural acuity. Smoking history and prevalence of significant left main coronary artery disease were similar between women and men.

Intraoperative characteristics differed between women and men (Table 2). Bypass and crossclamp times were slightly shorter for women compared with men, although women returned to bypass more frequently than men $(2.6 \%$ vs $1.7 \%, P<.001)$ and received intra-aortic balloon pumps more commonly in the intraoperative or postoperative period $(2.2 \%$ vs $1.4 \%, P<.001)$. Women were administered a greater median net prime volume indexed to BSA, greater total fluid, and a lower median volume of ultrafiltration. Acute normovolemic hemodilution, a blood conservation strategy, was used less commonly among women $(9.0 \%$ vs $15.7 \%)$. Median nadir Hct was lower among women $(22.1 \%$ vs $26.9 \%, P<.001)$. Less than half $(48.0 \%)$ of women reached a nadir Hct less than 21 , compared with only $13.3 \%$ of men, whereas women were administered significantly more intraoperative RBC transfusions $(33.7 \%$ vs $8.1 \%, P<.001)$.

Initial postoperative Hct was $28.0 \%$ in women and $32.0 \%$ in men, whereas median postoperative creatinine was 0.9 for women and 1.1 for men (both $P<.001$ ) (Table 3). Significantly more women exhibited stage 2 or 3 AKI than men $(6.0 \%$ vs $4.3 \%, P<.001)$. Women had higher rates for prolonged ventilation, postoperative renal replacement therapy, low cardiac output, RBC transfusion, pneumonia, sepsis, and hospital mortality. Although men were more likely to have new-onset atrial fibrillation, women had longer stays in both the intensive care unit and hospital and were at a higher risk for readmission.

After adjustment, sex did not modify the relationship between nadir Hct and the risk of AKI $(P=.67$, full multivariable table in Table E2). Lower nadir Hct was inversely associated with AKI (adjusted OR per 1-unit increase in nadir Hct 0.96; 95\% CI, 0.93-0.98), and this adjusted effect was similar across women (adjusted OR, 0.96; 95\% CI, 0.94-0.99) and men (adjusted OR, 0.96; 95\% CI, 0.93-0.98) (Figure 1). In sensitivity analyses, the interaction between nadir Hct and sex remained nonsignificant both for patients who received intraoperative RBC transfusion $(P=.88)$ and for those who did not $(P=.32)$.

\section{Discussion}

We used our multi-institutional quality improvement collaborative to investigate whether sex modified the relationship between nadir Hct on CPB and AKI among patients undergoing isolated CABG. Relative to men, women were more likely to be exposed to a lower Hct, to receive $\mathrm{RBC}$ transfusions, and to develop postoperative AKI. Women were also at higher risk for nearly every other postoperative complication compared with men, except for new-onset atrial fibrillation. As expected, nadir Hct was inversely associated with AKI. However, in contrast to the prior series evaluating $\mathrm{CABG}$ and valve operations, ${ }^{9}$ sex did not modify the relationship between nadir Hct and AKI for patients undergoing isolated $\mathrm{CABG}$, a finding independent of intraoperative $\mathrm{RBC}$ transfusions. 
TABLE 2. Intraoperative variables

\begin{tabular}{|c|c|c|c|}
\hline Variable & Female & Male & $P$ value \\
\hline No. of procedures & 4226 & 13,137 & \\
\hline \multicolumn{4}{|l|}{ No. of distal anastomoses } \\
\hline 1 & 3.2 & 1.6 & \\
\hline 2 & 20.9 & 15.0 & \\
\hline 3 & 44.8 & 41.8 & \\
\hline \multirow[t]{2}{*}{$4+$} & 31.2 & 41.6 & \\
\hline & & & $<.001$ \\
\hline $\mathrm{CPB}$ duration, min, median [IQR] & 90 [69-117] & $93[73-121]$ & $<.001$ \\
\hline Crossclamp duration, min, median [IQR] & $68[52-89]$ & $71[55-93]$ & $<.001$ \\
\hline Returned to bypass, $\%$ & 2.6 & 1.7 & $<.001$ \\
\hline \multicolumn{4}{|l|}{ IABP, $\%$ yes } \\
\hline Preoperative & 7.3 & 6.7 & \\
\hline Intraoperative & 1.7 & 1.2 & \\
\hline \multirow[t]{2}{*}{ Postoperative } & 0.5 & 0.2 & \\
\hline & & & .0008 \\
\hline Pulsatile perfusion, $\%$ yes & 0.8 & 0.8 & .80 \\
\hline \multicolumn{4}{|l|}{ Strategies to manage hemodilution } \\
\hline Static prime volume per BSA, $\mathrm{mL} / \mathrm{m}^{2}$, median $[\mathrm{IQR}]$ & $552[467-667]$ & $511[428-604]$ & $<.001$ \\
\hline Retrograde autologous priming, $\%$ yes & 77.9 & 79.2 & .051 \\
\hline Retrograde autologous priming, mL, median [IQR] & $550[400-700]$ & $600[400-700]$ & $<.001$ \\
\hline Net prime volume* per BSA, $\mathrm{mL} / \mathrm{m}^{2}$, median [IQR] & $407[282-566]$ & $363[251-498]$ & $<.001$ \\
\hline Total fluid administration, $\nmid \mathrm{mL}$, median [IQR] & $1000[560-1700]$ & $938[518-1600]$ & $<.001$ \\
\hline \multicolumn{4}{|l|}{ Blood management strategies } \\
\hline Conventional ultrafiltration, $\%$ yes & 23.1 & 21.8 & .073 \\
\hline Volume if performed, mL, median [IQR] & $1200[700-2050]$ & $1400[800-2500]$ & $<.001$ \\
\hline Cell-saving device, $\%$ yes & 85.4 & 85.0 & .49 \\
\hline Acute normovolemic hemodilution, $\%$ yes & 9.0 & 15.7 & $<.001$ \\
\hline Volume, mL, median [IQR] & $450[400-500]$ & $450[450-900]$ & $<.001$ \\
\hline Cardiotomy suction, $\%$ yes & 61.5 & 59.3 & .022 \\
\hline Blood-based cardioplegia, \% yes & 75.9 & 74.3 & .026 \\
\hline Total cardioplegia volume, mL, median [IQR] & $2000[1300-2800]$ & $2136[1450-3090]$ & $<.001$ \\
\hline
\end{tabular}

Lowest core temperature $\ddagger$

$\begin{array}{lrr}\text { Severe hypothermia } & 0.3 & 0.3 \\ \text { Moderate hypothermia } & 4.7 & 3.4 \\ \text { Mild hypothermia } & 67.7 & 67.7 \\ \text { Normothermia } & 27.3 & 28.6\end{array}$

\begin{tabular}{lcc} 
& & .0013 \\
\hline Furosemide use, \% yes & 4.5 & 5.4 \\
\hline Sodium bicarbonate total dose, mg, median [IQR] & $50[40-50]$ & $50[40-50]$ \\
\hline Vasopressin, \% yes & 9.4 & .014 \\
Nadir Hct & & .16 \\
$\quad<19$ & 15.8 & 3.0 \\
$19-21$ & 32.2 & 10.3 \\
$22-24$ & 28.3 & 18.0 \\
$25-27$ & 15.3 & 25.6 \\
$28+$ & 8.4 & 43.2
\end{tabular}


TABLE 3. Postoperative outcomes

\begin{tabular}{|c|c|c|c|}
\hline Variable & Female & Male & $P$ value \\
\hline No. of procedures & 4226 & 13,137 & \\
\hline Hct, first in ICU, \%, median [IQR] & $28.0[25.0-31.0]$ & $32.0[28.0-35.0]$ & $<.001$ \\
\hline Postoperative creatinine, mg/dL, median [IQR] & $0.9[0.8-1.3]$ & $1.1[0.9-1.4]$ & $<.001$ \\
\hline \multicolumn{4}{|l|}{ Outcome, $\%$ yes } \\
\hline Death, in hospital & 3.4 & 1.6 & $<.001$ \\
\hline Reoperation for bleeding & 1.4 & 1.7 & .17 \\
\hline Prolonged ventilation & 11.1 & 7.1 & $<.001$ \\
\hline Need for ultrafiltration & 0.5 & 0.3 & .006 \\
\hline Need for dialysis & 1.8 & 1.3 & .02 \\
\hline AKI, stage $2 / 3$ & 6.0 & 4.3 & $<.001$ \\
\hline Low cardiac output* & 6.3 & 4.6 & $<.001$ \\
\hline \multicolumn{4}{|l|}{$\mathrm{RBC}$ use } \\
\hline None & 44.5 & 75.7 & \\
\hline Intraoperative only & 17.7 & 3.6 & \\
\hline Postoperative only & 21.8 & 16.2 & \\
\hline \multirow[t]{2}{*}{ Intraoperative and postoperative } & 16.0 & 4.5 & \\
\hline & & & $<.001$ \\
\hline Intraoperative RBC units (if transfused), median [IQR] & $2[1-2]$ & $1[0-2]$ & $<.001$ \\
\hline Postoperative RBC units (if transfused), median [IQR] & $2[1-2]$ & $2[1-3]$ & .76 \\
\hline Pneumonia & 3.0 & 2.4 & .02 \\
\hline New-onset atrial fibrillation & 23.1 & 27.1 & $<.001$ \\
\hline Sepsis & 1.3 & 0.8 & .01 \\
\hline \multicolumn{4}{|l|}{ Intensive care unit, $\mathrm{d}$} \\
\hline$<1$ & 22.6 & 28.2 & \\
\hline $1-2$ & 23.1 & 25.9 & \\
\hline $2-3$ & 19.4 & 20.0 & \\
\hline $3-4$ & 12.6 & 10.2 & \\
\hline \multirow[t]{2}{*}{$4+$} & 22.3 & 15.8 & \\
\hline & & & $<.001$ \\
\hline Postoperative hospital d, median [IQR] & $6[5-8]$ & $6[5-7]$ & $<.001$ \\
\hline Readmission, $\%$ & 5.7 & 3.6 & $<.001$ \\
\hline
\end{tabular}

$\overline{H c t}$, Hematocrit; $I C U$, intensive care unit; $I Q R$, interquartile range; $A K I$, acute kidney injury; $R B C$, red blood cell. *Low cardiac output defined as the return to bypass, $\geq 2$ inotropes at 48 hours, or use of an intraoperative or postoperative intra-aortic balloon pump.

We acknowledge several limitations to our present study. First, although we adjusted for commonly reported risk factors, we cannot rule out the effect of unmeasured confounding. Second, we acknowledge that a number of potential mechanisms may contribute to the development of AKI (eg, hypotension, preoperative volume status, nephrotoxins); nonetheless, we evaluated the role of a number of factors likely contributing to hemodilution (eg, administration of priming fluid, cardioplegia, total fluid administration). Third, although other studies have evaluated AKI incidence and staging using urine output, we report previously established creatinine-based criteria. Fourth, because of the large size of our dataset, we recognize that some statistically significant differences in sex across many characteristics (eg, prime volume per BSA, retrograde autologous priming volume) are small in absolute magnitude and thus unlikely to be clinically relevant.
Multiple single-center studies have demonstrated an increased risk of AKI associated with a lower intraoperative Hct, including cohorts consisting of cardiac surgery using $\mathrm{CPB}^{8,12}$ and those limited to isolated CABG. ${ }^{13,14}$ One multicenter study of patients undergoing isolated CABG not only found nadir Hct to be independently associated with postoperative renal failure and low cardiac output syndrome but also found female sex to be associated with increased mortality on multivariable analysis. ${ }^{15}$ Few prior studies have assessed the effect of sex on the wellestablished relationship between nadir Hct and AKI. The studies exploring the relationship between nadir Hct and AKI have divided patients into 2 of 3 cohorts and established various threshold Hct values that conferred harm, for example, concluding those with Hct less than $21 \%$ or greater than $25 \%$ have increased risk of dialysis, ${ }^{12}$ hemodilution to Hct less than $24 \%$ associated with increased 


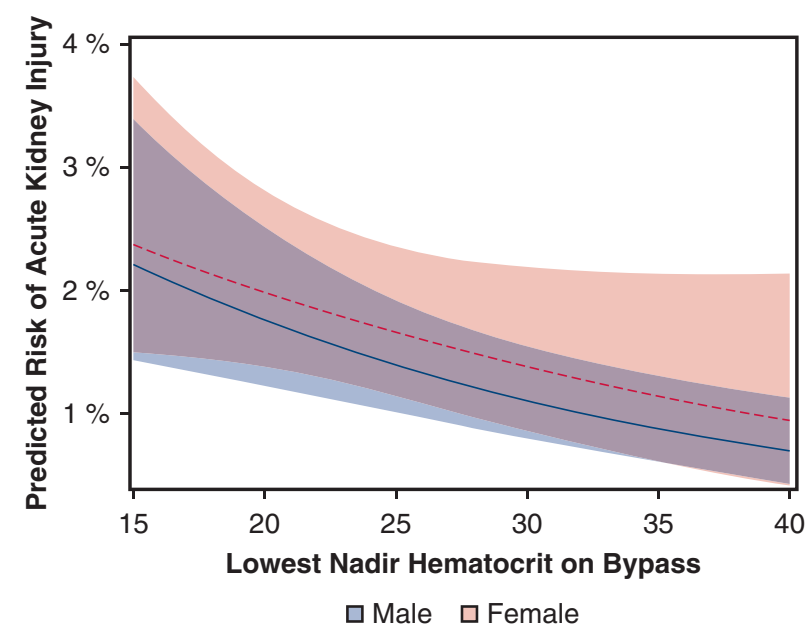

FIGURE 1. Relationship between nadir Hct during CPB and risk of stage 2 or 3 AKI. The predicted probability of AKI is plotted for male patients (solid line) and female patients (dashed line), along with 95\% CIs (shaded areas). The model adjusted for preoperative and intraoperative factors, as well as hospital variation.

likelihood of renal injury, ${ }^{14}$ and Hct greater than $21 \%$ deemed safe for renal function ${ }^{16}$ in 3 separate analyses. In contrast to these studies, we evaluate Hct as a continuous variable across the entire range of nadir values, which allows assessment of AKI risk across all Hct and not as a binary variable.

One large single-center study by Mehta and colleagues ${ }^{8}$ examined the effect of sex on the relationship between nadir Hct and AKI among 13,734 cardiac surgical patients. The authors found that nadir Hct was significantly associated with AKI in both men and women, albeit women had a lower nadir Hct during CPB. The authors further concluded that exposure to Hct $22 \%$ or less during $\mathrm{CPB}$ was associated with a nonsignificant increased rate of AKI among men, although this relationship did not persist when stratified by transfusion status. Ellis and colleagues ${ }^{9}$ used the PERForm registry to assess the relationship between nadir Hct and AKI among patients undergoing a variety of cardiac surgical procedures. The authors concluded that lower nadir Hct was associated with an increased risk of AKI among both men and women. Additionally, sex modified the relationship between nadir Hct and AKI; the odds of AKI was significantly lower in women than men at a given nadir Hct. In contrast to the study by Mehta and colleagues, ${ }^{8}$ this relationship persisted after adjusting for RBC transfusion. Nonetheless, the majority of men in the series by Ellis and colleagues ${ }^{9}$ underwent isolated CABG $(57.1 \%$ vs $41.3 \%$ ), whereas far fewer men underwent isolated valve procedures $(22.6 \%$ vs $38.1 \%)$. The fundamental pathophysiology of coronary disease and valvular dysfunction vastly differs, which may confound the apparent relationship between nadir Hct during CPB and AKI for both men and women. The present analysis furthers our understanding of the relationship between nadir Hct and AKI by assessing whether the demonstrated interaction by sex persists among patients presenting for treatment of their coronary disease. Notably, we conclude that the aforementioned interaction by sex was not significant, and that the inverse relationship between nadir Hct and AKI persisted

17,363 non-dialysis patients undergoing isolated coronary bypass

(2011-2016) from 41 centers

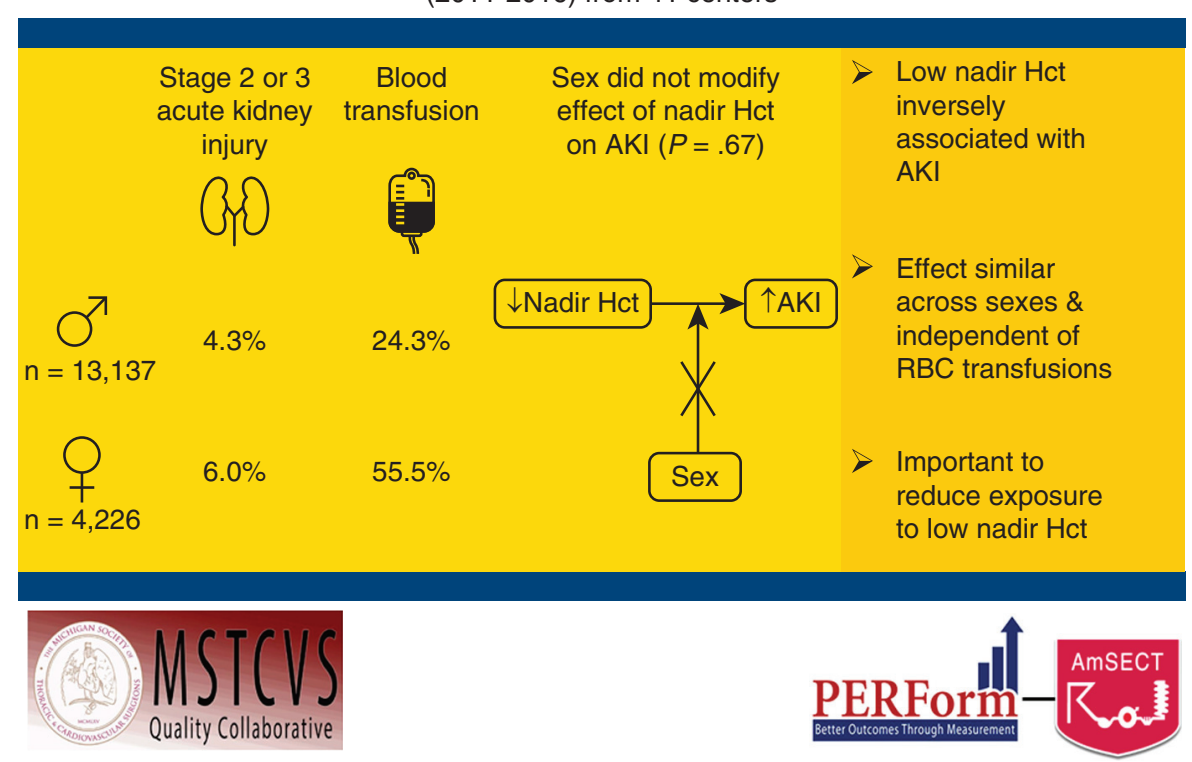

FIGURE 2. Visual abstract showing rates of stage 2 or $3 \mathrm{AKI}$ and blood transfusions by sex, interaction of sex on the relationship between nadir Hct and $\mathrm{AKI}$, and study conclusions (right). AKI, Acute kidney injury; Hct, hematocrit; RBC, red blood cell. 
across men and women, and independent of $\mathrm{RBC}$ transfusions.

A number of reasons might help explain why our present findings differ from those reported by Ellis and colleagues. ${ }^{9}$ The difference in outcome in the effect of sex on the relationship between nadir Hct and AKI may be due to the difference in surgical procedures, involved centers, and time period. Specifically, Ellis and colleagues ${ }^{9}$ included 15,221 patients across 26 centers who underwent a variety of surgical procedures (ie, CABG, valve, or CABG/valve) between 2010 and 2014, whereas the present analysis examined 17,363 patients undergoing isolated CABG across 41 centers between 2011 and 2016. Additionally, the effect demonstrated in the analysis by Ellis and colleagues ${ }^{9}$ did not persist among those patients who did not receive intraoperative $\mathrm{RBC}$ transfusion $(P=.16)$. The effect of sex in our analysis was nonsignificant for patients who received intraoperative RBC transfusion $(P=.88)$ and patients who did not $(P=.32)$.

Although one may expect women to reach a lower nadir Hct intraoperatively because they began with lower Hct preoperatively, our data showing increased risk of AKI with lower nadir Hct across sexes should prompt enhanced fluid restrictive management strategies for women, because they did not appear to have sex-related renal protective mechanisms during $\mathrm{CABG}$ and may enter the operation at increased risk for postoperative AKI. In contrast, the administered net prime volume adjusted for BSA was higher for women than men (407 vs $\left.363 \mathrm{~mL} / \mathrm{m}^{2}, P<.001\right)$. Additionally, only $9 \%$ of women underwent acute normovolemic hemodilution, despite approximately $80 \%$ of women presenting with an Hct greater than $33 \%$. Our data show that teams were less willing to attempt blood conservation techniques and more likely to transfuse RBCs in women than in men. The preoperative risk factors carried by women were compounded by intraoperative management strategies and resulted in a higher rate of AKI in women $(6.0 \%$ vs $4.3 \%, P<.001)$.

This multicenter observational study reinforces the potential harmful associated sequelae due to low nadir Hct during CPB. We found that women were administered more net prime volume per BSA intraoperatively, reached lower nadir Hct, and had higher rates of stage 2 and 3 AKI postoperatively, in addition to being at higher risk for nearly every postoperative complication.

\section{CONCLUSIONS}

We report that in an isolated CABG population, no effect of sex was found on the established inverse relationship between nadir Hct and AKI, a finding that persisted after adjustment for RBC transfusions (Figure 2). These data indicate that the same deleterious effects of low Hct persist across sexes and reinforce the importance of reducing exposure to low nadir Hct on CPB.

\section{Conflict of Interest Statement}

H.J.P. is a consultant for WL Gore, Medtronic, and Terumo. All other authors have nothing to disclose with regard to commercial support.

\section{References}

1. Rosner MH, Okusa MD. Acute kidney injury associated with cardiac surgery. Clin J Am Soc Nephrol. 2006;1:19-32.

2. Ryden L, Ahnve S, Bell M, Hammar N, Ivert TM, Sartipy U, et al. Acute kidney injury after coronary artery bypass grafting and long-term risk of myocardial infarction and death. Int J Cardiol. 2014;172:190-5.

3. Gallagher S, Jones DA, Lovell MJ, Hassan S, Wragg A, Kapur A, et al. The impact of acute kidney injury on midterm outcomes after coronary artery bypass graft surgery: a matched propensity score analysis. J Thorac Cardiovasc Surg. 2014;147:989-95.

4. Dardashti A, Ederoth P, Algotsson L, Bronden B, Bjursten H. Incidence, dynamics, and prognostic value of acute kidney injury for death after cardiac surgery. J Thorac Cardiovasc Surg. 2014:147:800-7.

5. Brown JR, Hisey WM, Marshall EJ, Likosky DS, Nichols EL, Everett AD, et al. Acute kidney injury severity and long-term readmission and mortality after cardiac surgery. Ann Thorac Surg. 2016;102:1482-9.

6. Ryden L, Sartipy U, Evans M, Holzmann MJ. Acute kidney injury after coronary artery bypass grafting and long-term risk of end-stage renal disease. Circulation. 2014:130:2005-11.

7. Karkouti K. Transfusion and risk of acute kidney injury in cardiac surgery. $\mathrm{Br} \mathrm{J}$ Anaesth. 2012;109(Suppl 1):29-38.

8. Mehta RH, Castelvecchio S, Ballotta A, Frigiola A, Bossone E, Ranucci M. Association of gender and lowest hematocrit on cardiopulmonary bypass with acute kidney injury and operative mortality in patients undergoing cardiac surgery. Ann Thorac Surg. 2013;96:133-40.

9. Ellis MC, Paugh TA, Dickinson TA, Fuller J, Chores J, Paone G, et al. Nadir hematocrit on bypass and rates of acute kidney injury: does sex matter? Ann Thorac Surg. 2015;100:1549-55.

10. Paugh TA, Dickinson TA, Theurer PF, Bell GF, Shann KG, Baker RA, et al. Validation of a perfusion registry: methodological approach and initial findings. J Extra Corpor Technol. 2012;44:104-15.

11. Mehta RL, Kellum JA, Shah SV, Molitoris BA, Ronco C, Warnock DG, et al. Acute Kidney Injury Network: report of an initiative to improve outcomes in acute kidney injury. Crit Care. 2007;11:R31.

12. Karkouti K, Beattie WS, Wijeysundera DN, Rao V, Chan C, Dattilo KM, et al. Hemodilution during cardiopulmonary bypass is an independent risk factor for acute renal failure in adult cardiac surgery. J Thorac Cardiovasc Surg. 2005; 129:391-400.

13. Swaminathan M, Phillips-Bute BG, Conlon PJ, Smith PK, Newman MF, Stafford-Smith M. The association of lowest hematocrit during cardiopulmonary bypass with acute renal injury after coronary artery bypass surgery. Ann Thorac Surg. 2003;76:784-92.

14. Habib RH, Zacharias A, Schwann TA, Riordan CJ, Engoren M, Durham SJ, et al. Role of hemodilutional anemia and transfusion during cardiopulmonary bypass in renal injury after coronary revascularization: implications on operative outcome. Crit Care Med. 2005;33:1749-56.

15. Ranucci M, Biagioli B, Scolletta S, Grillone G, Cazzaniga A, Cattabriga I, et al. Lowest hematocrit on cardiopulmonary bypass impairs the outcome in coronary surgery. Tex Heart Inst J. 2006;33:300-5.

16. Ariturk C, Ozgen ZS, Kilercik M, Ulugol H, Okten EM, Aksu U, et al. Comparative effects of hemodilutional anemia and transfusion during cardiopulmonary bypass on acute kidney injury: a prospective randomized study. Heart Surg Forum. 2015;18:E154-60.

Key Words: nadir hematocrit, acute kidney injury, coronary artery bypass grafting, cardiopulmonary bypass, blood conservation, blood transfusion 


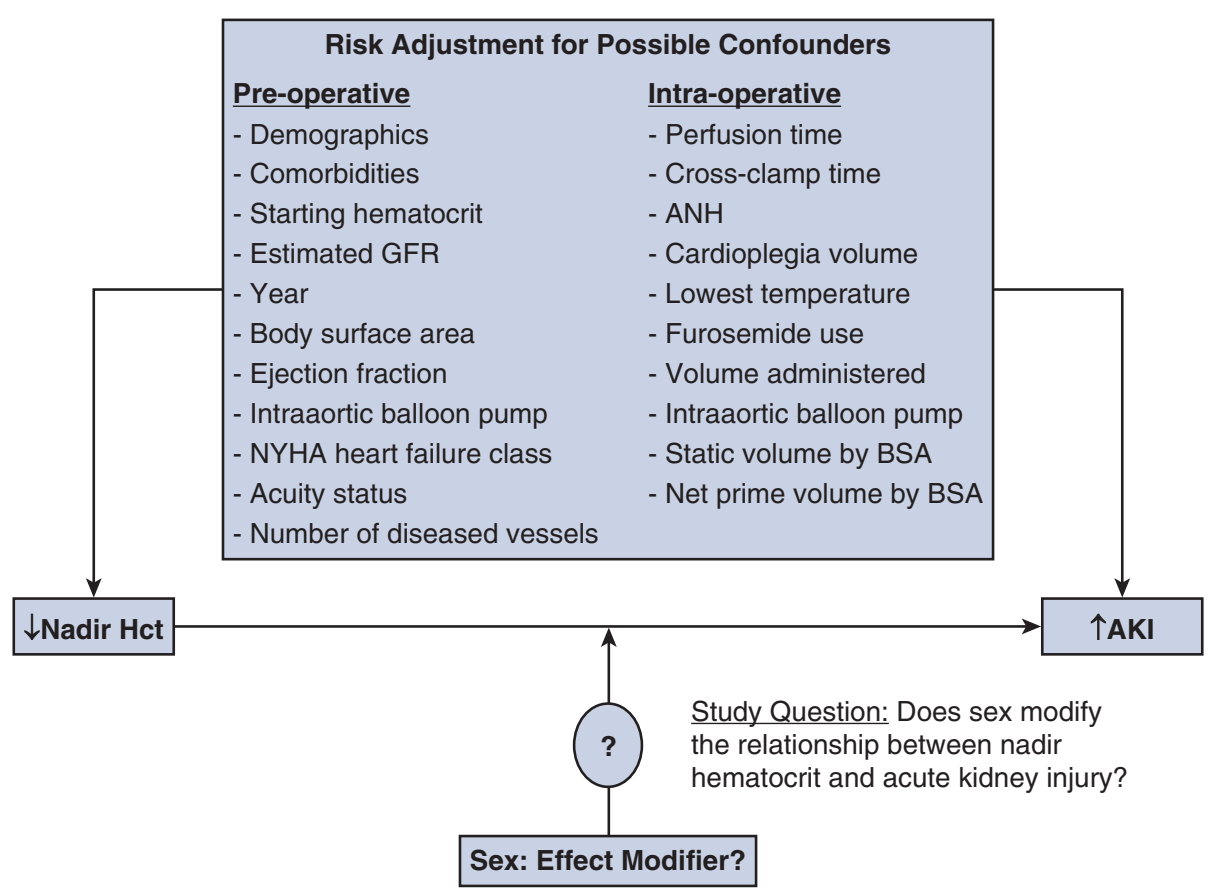

FIGURE E1. Conceptual model showing the research question of whether sex functions as an effect modifier on the known strong inverse relationship between nadir Hct on CPB and postoperative AKI. GFR, Glomerular filtration rate; NYHA, New York Heart Association; ANH, acute normovolemic hemodilution; $B S A$, body surface area; $H c t$, hematocrit; $A K I$, acute kidney injury. 
TABLE E1. Missing observations for variables included in the final model, stratified by sex and with imputation methods listed, if applicable

\begin{tabular}{|c|c|c|c|}
\hline Variable & $\begin{array}{c}\text { Female missing } \\
\text { observations, } \\
\text { total } \mathbf{n}=4226(\%)\end{array}$ & $\begin{array}{c}\text { Male missing } \\
\text { observations, } \\
\text { total } \mathbf{n}=13,137(\%)\end{array}$ & $\begin{array}{c}\text { Method of imputation, } \\
\text { if performed }\end{array}$ \\
\hline Nadir Hct, median & $47(1.1)$ & $95(0.7)$ & Median by sex \\
\hline Vascular disease, $\%$ & $2(0.05)$ & $2(0.02)$ & No imputation \\
\hline Moderate to severe COPD, \% & $74(1.8)$ & $198(1.5)$ & No imputation \\
\hline Preoperative Hct, median & $28(0.7)$ & $62(0.5)$ & Median by sex \\
\hline WBC count, mean & $32(0.8)$ & $71(0.5)$ & Median by sex \\
\hline $\mathrm{CPB}$ duration, median & $5(0.1)$ & $4(0.03)$ & Median by sex \\
\hline Crossclamp duration, median & $88(2.1)$ & $175(1.3)$ & Median by sex \\
\hline Static volume, median mL & $75(1.8)$ & $180(1.4)$ & Median by sex \\
\hline Total fluid administration, median $\mathrm{mL}$ & $315(7.5)$ & $904(6.9)$ & Median by sex \\
\hline Acute normovolemic hemodilution, $\%$ & $245(5.8)$ & $622(4.7)$ & Missing imputed as "no" \\
\hline Total cardioplegia volume, median $\mathrm{mL}$ & $187(4.4)$ & $462(3.5)$ & Median by sex \\
\hline Lowest core temperature, median ${ }^{\circ} \mathrm{F}$ & $50(1.2)$ & $93(0.7)$ & Mode $\left(\geq 35^{\circ} \mathrm{F}\right)$ imputed \\
\hline Total prime volume, median $\mathrm{mL}$ & $96(2.3)$ & $221(1.7)$ & Median by sex \\
\hline
\end{tabular}

Hct, Hematocrit; $C O P D$, chronic obstructive pulmonary disease; $W B C$, white blood cell; $C P B$, cardiopulmonary bypass. 
TABLE E2. Multivariable generalized linear mixed effect model output

\begin{tabular}{|c|c|c|c|c|}
\hline Variable & Estimate & Standard error & t value & $P$ value \\
\hline \multicolumn{5}{|l|}{ Year } \\
\hline 2011 & 0.2877 & 0.1945 & 1.48 & .1391 \\
\hline 2012 & 0.1769 & 0.146 & 1.21 & .2258 \\
\hline 2013 & -0.00635 & 0.1366 & -0.05 & .9629 \\
\hline 2014 & -0.00303 & 0.1244 & -0.02 & .9806 \\
\hline 2015 & 0.2209 & 0.1136 & 1.94 & .0518 \\
\hline 2016 & 0 & & & \\
\hline Age, median y & 0.01823 & 0.004384 & 4.16 & $<.0001$ \\
\hline $\operatorname{BSA}\left(\mathrm{m}^{2}\right)$ & 1.0744 & 0.2017 & 5.33 & $<.0001$ \\
\hline Diabetes & 0.293 & 0.08165 & 3.59 & .0003 \\
\hline Peripheral vascular disease & 0.1552 & 0.09572 & 1.62 & .105 \\
\hline Chronic lung disease & 0.4771 & 0.1018 & 4.69 & $<.0001$ \\
\hline Preoperative Hct, median \% & -0.04097 & 0.008797 & -4.66 & $<.0001$ \\
\hline Hypertension & 0.1487 & 0.1533 & 0.97 & .3322 \\
\hline \multicolumn{5}{|l|}{$\mathrm{EGFR}, \mathrm{mL} / \mathrm{min} / 1.73 \mathrm{~m}^{2}$} \\
\hline$\geq 90$ & -2.5981 & 0.3843 & -6.76 & $<.0001$ \\
\hline $60-90$ & -2.9167 & 0.3806 & -7.66 & $<.0001$ \\
\hline $30-60$ & -2.5684 & 0.3816 & -6.73 & $<.0001$ \\
\hline $15-30$ & -1.1354 & 0.4031 & -2.82 & .0049 \\
\hline$<15$ & 0 & & & \\
\hline \multicolumn{5}{|l|}{ Last white blood cell count $\times 10^{9} / \mathrm{L}$, median } \\
\hline$<4.5$ & -0.2796 & 0.2253 & -1.24 & .2146 \\
\hline$\geq 4.5$ and $\leq 10$ & -0.1732 & 0.09652 & -1.79 & .0728 \\
\hline$>10$ & 0 & & & \\
\hline $\mathrm{CHF}$ & 0.278 & 0.1507 & 1.84 & .0652 \\
\hline NYHA class III-IV & 0.09068 & 0.165 & 0.55 & .5826 \\
\hline \multicolumn{5}{|l|}{ Left ventricle ejection fraction, $\%$} \\
\hline$<40$ & 0.3685 & 0.1192 & 3.09 & .002 \\
\hline $40-49$ & 0.2886 & 0.1172 & 2.46 & .0138 \\
\hline $50-59$ & 0.07976 & 0.1003 & 0.8 & .4264 \\
\hline$\geq 60$ & 0 & & & \\
\hline \multicolumn{5}{|l|}{ Acuity } \\
\hline Elective & -0.4597 & 0.2011 & -2.29 & .0223 \\
\hline Urgent & -0.4052 & 0.1881 & -2.15 & .0312 \\
\hline Emergency/salvage & 0 & & & \\
\hline $3+$ diseased vessels & 0.03741 & 0.1004 & 0.37 & .7096 \\
\hline Perfusion time, min, median & 0.009287 & 0.001678 & 5.53 & $<.0001$ \\
\hline Crossclamp time, min, median & -0.00627 & 0.002316 & -2.71 & .0068 \\
\hline Static volume per BSA, $\mathrm{mL} / \mathrm{m}^{2}$, median & 0.0002 & 0.000498 & 0.4 & .6878 \\
\hline Intra-aortic balloon pump & 0.4528 & 0.1199 & 3.78 & .0002 \\
\hline Total fluid administration, $\mathrm{mL}$, median & -0.00006 & 0.000037 & -1.64 & .1015 \\
\hline Acute normovolemic hemodilution, $\%$ yes & -0.1429 & 0.1573 & -0.91 & .3637 \\
\hline Total cardioplegia volume, $\mathrm{mL}$, median & 0.000033 & 0.000022 & 1.53 & .1257 \\
\hline \multicolumn{5}{|l|}{ Lowest temperature on bypass, ${ }^{\circ} \mathrm{C}$} \\
\hline Severe hypothermia $(<28)$ & 0.7353 & 0.4883 & 1.51 & .1321 \\
\hline Moderate hypothermia $(\geq 28$ and $<32)$ & 0.06801 & 0.2085 & 0.33 & .7443 \\
\hline Mild hypothermia $(\geq 32$ and $<35$ ) & -0.04016 & 0.09781 & -0.41 & .6814 \\
\hline
\end{tabular}


TABLE E2. Continued

\begin{tabular}{|c|c|c|c|c|}
\hline Variable & Estimate & Standard error & t value & $P$ value \\
\hline Normothermia $(\geq 35)$ & 0 & . & . & . \\
\hline Furosemide use & 0.5675 & 0.1623 & 3.5 & .0005 \\
\hline Net prime volume by BSA, $\mathrm{mL} / \mathrm{m}^{2}$, median & 0.000285 & 0.000244 & 1.17 & .2427 \\
\hline Nadir Hct & -0.03727 & 0.02163 & -1.72 & .0848 \\
\hline Male sex & 0.06987 & 0.5031 & 0.14 & .8896 \\
\hline Nadir Hct and sex interaction term & -0.00944 & 0.02217 & -0.43 & .6704 \\
\hline Nadir Hct given female & -0.0327 & 0.967829 & & \\
\hline Nadir Hct given male & -0.04671 & 0.954364 & & \\
\hline Model intercept & -2.2147 & 0.9288 & -2.38 & .0221 \\
\hline
\end{tabular}

BSA, Body surface area; $H c t$, hematocrit; EGFR, estimated glomerular filtration rate; $C H F$, congestive heart failure; NYHA, New York Heart Association. 